\title{
Princípios e valores implicados na prática da sedação paliativa e a eutanásia
}

Melisse Eich ${ }^{(a)}$

Marta Inez Machado Verdi ${ }^{(b)}$

Mirelle Finkler ${ }^{(\mathrm{c})}$

Pedro Paulo Scremin Martins(d)

Eich $M$, Verdi MIM, Finkler $M$, Martins PPS. The principles and values implied in the practice of palliative sedation and the euthanasia. Interface (Botucatu). 2018; 22(66):733-44.

The aim of the present study was to investigate the meaning attributed by healthcare professionals to the practice of palliative sedation in the dying process, the relationship of this practice with euthanasia, and the values considered important and that ground decision making by palliative care teams. This is an exploratory and descriptive qualitative study, based on dialectical hermeneutics. The results show that the meanings attributed by the interviewed professionals were in line with scientific development. They reported that they sought to clarify the clinical facts involved in each decisionmaking process and the implicated values according to the evolution of ethical reflections regarding the practice of palliative sedation and euthanasia. Within the scope of ethical reflection, principles are not considered absolute, because, when considering as values, professionals analyzed the specific circumstances and the consequences involving their decisions.

Keywords: Deep sedation. Palliative care. Bioethics. Euthanasia.
Este estudo buscou compreender os sentidos atribuídos, pelos profissionais de saúde, à prática da sedação paliativa no processo de morrer, as relações desta prática com a eutanásia, bem como os valores considerados importantes e que subsidiam a equipe de cuidados paliativos na tomada de decisão. Trata-se de uma pesquisa exploratória e descritiva de abordagem qualitativa, baseada na hermenêutica dialética. Os resultados indicam que os sentidos atribuídos pelos profissionais entrevistados acompanham o desenvolvimento científico, os quais têm buscado esclarecer os fatos clínicos de cada processo de tomada de decisão e os valores implicados, seguindo a evolução da reflexão ética sobre a prática da sedação paliativa e eutanásia. No âmbito da reflexão ética, os princípios não são vistos como absolutos, pois, ao considerarem os valores, os profissionais analisam as circunstâncias e as consequências que permeiam as decisões.

Palavras-chave: Sedação profunda. Cuidados paliativos. Bioética. Eutanásia.

\footnotetext{
(a) Programa de PósGraduação em Saúde Coletiva, Departamento de Saúde Pública Centro de Ciências da Saúde, Universidade Federal de Santa Catarina (UFSC). Rua Itapiranga, 200, Apto 704, Itacorubi. Florianópolis, SC, Brasil. 88034-

480. meliseeich@ hotmail.com (b) Departamento de Saúde Pública, Centro de Ciências da Saúde, UFSC. Florianópolis, SC, Brasil. marta.verdi@ufsc.br

(c) Departamento de Odontologia, Centro de Ciências da Saúde, UFSC. Florianópolis, SC, Brasil.mirellefinkler@ yahoo.com.br

(d) Graduando do curso de Filosofia, UFSC. Florianópolis, SC, Brasil. ppsm29@hotmail.com
} 


\section{Introdução}

Os cuidados paliativos (CP), enquanto "um direito humano básico e um componente essencial de cuidados abrangentes e integrados"1 (p. 45), defendem que as pessoas em fim de vida tenham acesso aos recursos técnico-científicos e humanos que favorecem o cuidado para a morte digna. Dentre tais recursos está a sedação paliativa (SP) que, de modo geral, considera-se deva ser discutida por todos os profissionais envolvidos no processo, a partir da competência de cada um.

Atendida essa condição, acredita-se que a SPm como recurso dos CP para melhorar a qualidade de vida das pessoas doentes e seus familiares, implica "Reconhecer que todas as pessoas próximas do fim da vida desejam ser tratadas como pessoas de valor pelos profissionais da saúde e ter uma atenção especializada, direcionada para manter a dignidade, incentivar a independência, aliviar os sintomas e maximizar o conforto ${ }^{2 "}$ (p. 389).

Primeiramente, convém destacar que desde o surgimento da utilização da sedação em pessoas em fim de vida, uma evolução conceitual vem ocorrendo em virtude dos debates em torno dos estreitos limites entre a prática da SP e a eutanásia. O conceito foi apresentado inicialmente como "sedação terminal", em 1991, por Robert E. Enck no artigo intitulado Drug-induced Terminal Sedation for Symptom Controß e a partir daí se iniciou o inevitável debate sobre se a prática era ou não eutanásia4 . Uma das consequências desse debate foi a introdução do termo "Sedação Paliativa", realizada por Broeckaert, no artigo Palliative Sedation Defined or why and when terminal Sedation is not Euthanasia ${ }^{5}$. De fato, o termo "Sedação Paliativa" foi sugerido como alternativa porque o termo "Sedação Terminal" foi variavelmente definido podendo ser mal interpretado para sugerir que a sedação é usada para terminar a vida (eutanásia), e não para enfatizar a natureza refratária dos sintomas e seu uso pouco antes da morte ${ }^{6}$.

Possivelmente, em decorrência do debate, ainda hoje as terminologias "SP" e "sedação terminal" são distinguidas por alguns autores, enquanto outros as consideram como sinônimos. Concepções em consonância com a modalidade assistencial dos CP propõem o termo SP definido como: o uso monitorado de medicamentos destinados a induzirem um estado de consciência diminuído ou a inconsciência, com a intenção de proporcionar o alívio adequado dos sintomas refratários, que não podem ser adequadamente controlados por uma terapia tolerável que não comprometa a consciência ${ }^{7}$. Uma vez identificada a refratariedade dos sintomas e a possibilidade de oferta de uso da SP, os critérios técnicos sobre a prática, apesar de importantes, não são suficientes para uma tomada de decisão prudente. Nosso argumento é que, diante da tomada de decisão prudente sobre o uso ou não da SP, a reflexão ética revela-se essencial para elucidar os questionamentos que se impõem no processo de decisão e os princípios e valores que o alicerçam.

Aparentemente, é possível que muitos profissionais entendam que a prática da SP envolve apenas as questões técnicas relacionadas à prescrição/administração de medicamentos a uma pessoa com sofrimento incontrolável. Não excluímos que a SP - como recurso para minimizar o sofrimento e humanizar a morte - passe também por uma decisão técnica diante de um problema clínico. Entretanto, entendemos que é fundamental a reflexão ética sobre os fatos e valores na tomada de decisão, pois, conforme Gracia et al., os problemas éticos consistem em conflitos de valores, e promover os melhores valores possíveis é um dever ${ }^{8}$. Noutros termos, para um problema ético ser analisado, os fatos que lhe dão suporte (no qual os valores se apoiam) têm de estar claros para que possamos realizar o dever de optar pelos melhores valores. Diante dessa problemática, este estudo se propôs a compreender os sentidos que os profissionais de saúde atribuem ao recurso da SP durante o processo de morrer, as relações que fazem com a eutanásia, e verificar quais são os princípios e valores implicados na tomada de decisão sobre a SP por uma equipe de saúde de CP oncológicos.

Concordando com Rego e Palácios, acreditamos que o estudo é relevante, haja vista que "cabe ao campo da Saúde Coletiva/Saúde Pública contribuir para o planejamento de serviços e sistemas de saúde que contemplem a questão do cuidado no fim da vida"9 (p. 1756). De fato, tal modalidade de cuidado vem sendo difundida diante da crescente necessidade de assistência na finitude humana e não se restringe mais ao âmbito hospitalar. Tais cuidados são prestados em Hospice (centro de assistência 
exclusivo para pessoas em fim de vida) e, no próprio domicílio - como descrito por Floriani e Schramm sobre os desafios para se incluir os $C P$ na rede de atenção básica ${ }^{10}-$, e, mais recentemente, na Atenção Domiciliar.

\section{Metodologia}

Para refletir acerca do processo de decisões - sobre a prática da SP e sua relação com a eutanásia - no âmbito de uma equipe de saúde de CP oncológicos, desenvolvemos uma pesquisa exploratóriodescritiva de abordagem qualitativa, com base no método hermenêutico-dialético como um "caminho de pensamento", seguindo as etapas de operacionalização dessa abordagem proposta por Minayo: 1) elaboração de categorias analíticas; 2) ordenação e classificação dos dados; 3 ) leitura horizontal e transversal dos textos (entrevistas), e 4) análise final/relatório ${ }^{11}$.

O campo de pesquisa foi o setor de CP de um hospital da região Sul do Brasil. Os participantes do estudo foram os profissionais que integram a equipe de saúde: assistentes sociais, psicólogos, médicos, técnicos de enfermagem, farmacêuticos, nutricionistas, enfermeiros e fisioterapeutas, totalizando dez participantes. A seleção dos participantes teve como critério de inclusão: ter mais de dez anos de experiência profissional ou certificação em cuidados paliativos, e obter, no mínimo, um representante das diferentes categorias que integram a equipe. O critério de exclusão foi ter menos de dez anos de experiência ou não ter certificação em cuidados paliativos.

Em relação às limitações e potencialidades da pesquisa, ponderamos a necessidade de se produzir uma amostra representativa e aleatória. Com a finalidade de alcançar uma narrativa abrangente $e$ pluralista, obtivemos uma amostra que integrou a experiência, o conhecimento em cuidados paliativos e a diversidade de profissões que integram a equipe. Encerramos a coleta de dados, realizada por meio de entrevista semiestruturada, quando os objetivos do estudo foram alcançados.

No processo de análise, empregou-se o software de organização e análise de dados qualitativos, Atlas.ti 7.1.5. O processo analítico dos relatos de experiências dos participantes da pesquisa, realizado a partir do roteiro de entrevista semiestruturada, revelou a categoria temática, objeto de discussão neste artigo: os sentidos atribuídos à prática da SP e os princípios e valores implicados no processo.

Os participantes foram esclarecidos acerca do propósito e procedimentos da pesquisa e sobre a possibilidade de recusa de participação a qualquer momento, e, em seguida, manifestaram sua anuência mediante termo de consentimento livre e esclarecido (TCLE).

Os aspectos éticos da pesquisa - por envolver seres humanos - foram tratados conforme as normas e diretrizes do Conselho Nacional de Saúde (2013), que prevê a submissão do projeto à avaliação por comitê de ética em pesquisa envolvendo seres humanos ${ }^{12}$. O projeto foi submetido à avaliação e aprovado pelos Comitês de Éticas em Pesquisas com Seres Humanos (CEPSH), com Parecer $\mathrm{n}^{\circ}$. 550.595 e n $n^{\circ} .642 .272$.

\section{Resultados e discussão}

A interpretação da categoria temática que emergiu do processo de análise dos dados de entrevista foi dividida em duas subcategorias relacionadas à prática da SP: 1) sentidos atribuídos à prática da SP; 2) princípios e valores implicados na prática da SP e a eutanásia.

As subcategorias são discutidas à luz das contribuições de Gracia ${ }^{4,8}$ para a bioética clínica, e de pesquisadores cujos trabalhos enfocam a prática da SP, conforme revisão de literatura.

A fim de manter o anonimato dos entrevistados, as falas que sintetizaram respostas ao problema foram referenciadas pelos codinomes Violeta, Margarida, Girassol, Gardênia, Alecrim, Tulipa, Hortênsia, Lírio, Cravo, Orquídea.

A discussão revela o olhar dos trabalhadores de saúde sobre a prática da SP. 


\title{
Sentidos atribuídos à prática da sedação paliativa
}

\author{
No âmbito dos $\mathrm{CP}$,
}

Em fim de vida, os objetivos do cuidado podem mudar e o alívio do sofrimento pode predominar em relação a outras considerações relacionadas à capacidade funcional. Nessa configuração, a designação de um sintoma como 'refratário' pode justificar o uso da sedação paliativa, particularmente porque esta é a única opção que é capaz de fornecer o alívio necessário com certeza e rapidez $z^{7}$. (p. 1009)

A compreensão relatada pelos profissionais de saúde em relação à SP abrange os fatos clínicos como justificação, mas a decisão é permeada pelas questões éticas.

Os sentidos atribuídos pelos profissionais à prática da SP destacam, antes de tudo, o alívio do sofrimento enquanto objetivo principal. Para eles, a SP

“[...] é uma ferramenta para o alívio do sofrimento, quando após o uso de tudo o que nós temos disponível não é mais possível controlar os sintomas. [...] Nós tentamos controlá-los sempre que possível, e o nosso último recurso, quando esse sofrimento se torna realmente incompatível, oferecemos a sedação." (Gardênia)

Com o relato, se evidencia a compreensão da SP como último recurso para aliviar o sofrimento da pessoa doente com sintomas refratários, o qual "pode tanto ser um sofrimento físico quanto um sofrimento psicológico ou social ou mesmo espiritual" (Gardênia); isto vai ao encontro da definição de $\mathrm{CP}$ da $\mathrm{OMS}^{1}$ e da própria visão da precursora dos CP, Cicely Saunders ${ }^{2}$. Em outros termos, a prática da SP não é apenas um dos recursos dos $\mathrm{CP}$, mas um dos últimos a que se pode recorrer para se promover a "boa morte" ou a "morte digna" ao minimizar o sofrimento da pessoa doente, como afirma Alecrim:

"Sempre vamos acompanhando com o tratamento. Em alguns pacientes, o quadro se torna tal que todas as medidas que nós temos à disposição já foram usadas, não são efetivas e o sofrimento do paciente continua grande. Então, é a partir desse momento que começamos a pensar, para esse paciente, a SP; nunca vai ser a primeira opção."

Como se percebe, é somente quando todas as alternativas de abordagem para controle dos sintomas foram esgotadas ou os tratamentos standard estão associados a efeitos colaterais insuportáveis, é que o uso de SP passa a ser considerado pela equipe. Assim,

"Você vem acompanhando a evolução da doença; conhece a história clínica e terapêutica do paciente, sabe o que pode ser feito, e que chegou numa situação em que se tem a sedação ou nada, enquanto o paciente sofre; e é essa noção de que é necessário não permitir que uma pessoa sofra inutilmente até a morte, que nos leva a pensar que temos o último recurso: a SP." (Alecrim)

Permanece corroborado, na fala, o momento de avaliação da necessidade de SP, que é, segundo Mercadante et al., quando se identificam os sintomas refratários, que podem ser físicos ou psicoexistenciais ${ }^{13}$.

Esclarecido o momento de se realizar a SP, elucidaremos como ela deve ser realizada, isto é, os critérios técnicos e éticos a se seguirem.

Do ponto de vista técnico, há certo consenso, na literatura científica, de que a sedação ocorre em diferentes modalidades e é classificada em vários tipos, assim como o tipo de fármaco e as propriedades farmacológicas do sedativo escolhido.

De acordo com o Comitê de Ética da Sociedade Espanhola de Cuidados Paliativos, a sedação, genericamente falando, seus matizes, pode ser primária ou secundária, contínua ou intermitente, 
profunda ou superficial. Assim, a SP é classificada "segundo a temporalidade" (em sedação intermitente: permite períodos de alerta do paciente; e sedação contínua: mantém a diminuição do nível de consciência do paciente de forma permanente) e segundo a intensidade (em sedação superficial: permite a comunicação do paciente com as pessoas que a assistem; e sedação profunda: mantém o paciente em estado de inconsciência) ${ }^{14}$. Também, segundo o Guideline for Palliative Sedation da Royal Dutch Medical Association, a sedação contínua é o subtipo de maior alcance de SP, e visa reduzir a consciência da pessoa doente até o momento da morte ${ }^{15}$. Sem dúvida, a SP profunda e contínua, em fim de vida, é a que mais implica questões éticas, pois precisa ser claramente distinguida da abreviação da vida. Não por acaso, a SP profunda e contínua aparece no relato dos profissionais imbricada de conteúdo ético.

\begin{abstract}
"Nós dividimos os sintomas em difíceis e intoleráveis para o uso da sedação. Inclusive existem diferentes tipos de sedação, por exemplo, a sedação usada [...] é uma sedação profunda; poderíamos usar a intermitente; depende do objetivo, do estado do paciente e para fazer isso com segurança, precisamos conhecer a história do paciente, sua biografia e a história natural da doença, pois as duas coisas, permeando este processo é o que deixa o profissional tranquilo e a família e paciente, seguros quanto à opção da sedação." (Violeta)
\end{abstract}

Deduz-se que se propõe englobar - no processo de tomada de decisão sobre o uso da SP e a respectiva modalidade - a percepção e o respeito à singularidade dos sujeitos envolvidos, o que the dá, para além da classificação técnica, um conteúdo ético de respeito à autonomia. Conforme o relato, a SP na modalidade superficial e intermitente é utilizada quando há uma expectativa de melhora da pessoa doente, como corrobora Gardênia:

“[...] existem modalidades de sedação que é a modalidade de sedação leve, a sedação profunda e a sedação intermitente e contínua. Pacientes com perspectiva de receber alguma melhora podem utilizar uma sedação leve e intermitente. Mas noutra condição onde você entende que essa perspectiva de melhora - após o término do efeito da sedação não é vislumbrada acabamos optando pela sedação profunda."

Feita a distinção, podemos afirmar que, devido às peculiaridades dos CP, a SP profunda e contínua é a mais comumente utilizada, e que se caracteriza como último recurso em fim de vida. Resulta da compreensão dos profissionais da saúde sobre o uso da SP a afirmação de que o alívio do sofrimento é o objetivo do uso deste recurso no processo de morrer e no cuidado para a morte digna. Noutros termos, a prática da SP deve partir do entendimento de que seu uso decorre da evolução da doença e cujos sintomas são refratários. Diante desses sofrimentos, os profissionais compreendem que a SP passa a ser uma necessidade:

“É uma necessidade ter a SP. Dependendo do grau de evolução da doença, do estado e sofrimento do paciente, eu sou de acordo que precisa da SP. Ele precisa estar bem grave, em fase final de vida e num sofrimento intolerável, para a realização da SP. Seria um alívio para o sofrimento." (Cravo)

Esse é o ponto de vista que compartilhamos. Contudo, é importante ressaltar que a possibilidade de SP deve ser discutida previamente com a pessoa doente e seus familiares. Como atitude de respeito à autonomia, eles devem estar informados da necessidade/finalidade da SP, haja vista que a refratariedade dos sintomas é condição para se definir esta necessidade. Trata-se, em última instância, de uma prática inerente aos CP para mantê-los com todos os recursos disponíveis até a morte, como relata Hortênsia: "compreendo o uso da SP como mais um cuidado, como se fosse uma oferta de cuidado; seria eliminar o sofrimento extremo em uma situação extrema; seria manter o cuidado". 


\section{Princípios e valores implicados na prática da SP e a eutanásia}

Como vimos, a SP tem como característica a promoção do alívio do sofrimento como necessidade do cuidado. Portanto, nessa prática, não pode existir qualquer intenção de interferir na temporalidade do processo de morrer, mas tão somente intervir no sofrimento no sentido de minimizá-lo para promover a morte mais digna possível.

A não interferência no processo de morrer, que deve decorrer da própria evolução da doença, faz parte da intenção de uma equipe interdisciplinar. É o que os profissionais compartilham: "o intuito da SP não é apressar a morte em nenhum momento, pelo contrário, é trazer conforto para o paciente. Nós queremos ajudar; permitir que ele não tenha sofrimento" (Tulipa).

Sutilmente, esta intencionalidade se reveste de determinados princípios e valores, que visam afastar a prática da SP, da eutanásia. Nesse sentido, percebemos que há uma preocupação, efetiva, no âmbito da equipe, em distinguir adequadamente tais práticas, daí os aspectos éticos envolvidos.

Muitos autores, como Mercadante et al. ${ }^{13}$, Maltoni et al. ${ }^{16,17}$ e Chiu e colaboradores ${ }^{18}$, afirmam que a SP, especificamente a sedação contínua até o momento da morte, não tem por finalidade encurtar ou prolongar a vida, mas, sim, aliviar o sofrimento. Quando o sedativo adequado é aplicado em doses proporcionais, a SP não deve antecipar a morte e, por isso, é altamente recomendável na prática assistencial de CP prestados por equipes interdisciplinares.

O debate sobre a tênue linha entre sedação e eutanásia sempre esteve presente na literatura e por isso acreditamos ser de fundamental importância revelar o pensamento dos profissionais sobre a questão. Talvez mais atento ao debate, um dos profissionais argumentou, não apenas com base na experiência, mas, também, teórica, que a SP não abrevia a vida, diz ele: "os trabalhos que eu li sobre SP mostram que os pacientes sedados sobrevivem até mais que os não sedados e então isso aí para mim, por si só exclui essa proximidade que existe entre SP e eutanásia" (Gardênia).

A não abreviação da vida é um dos argumentos dos profissionais para o uso da SP. Mas não apenas isso. A vivência cotidiana do sofrimento das pessoas doentes integra o consenso de que a SP é o melhor e último recurso para minimizar o sofrimento delas, mas sempre colocando como condição o respeito à autonomia, pois

"Quem vive o sofrimento humano diariamente tem a certeza de que a melhor modalidade ou a única encontrada para aliviar o sofrimento, é a sedação. Até porque nada que você fizer a mais, vai modificar o rumo natural da doença. Então podemos deixar ele com sofrimento ou sem sofrimento. Se o doente prefere permanecer sem sofrimento podemos oferecer algo que o alivie; e se ele quer morrer com sofrimento, trabalhamos a equipe e se respeita a decisão dele." (Gardênia)

Quando o profissional refere que se "o doente quer morrer com sofrimento a equipe respeita a decisão dele" (Gardênia), compreendemos que não apenas os princípios bioéticos, como o do respeito à autonomia são considerados, mas, também, os valores. Os valores religiosos tiveram relevância em muitas falas de alguns entrevistados, como assevera Hortênsia:

\footnotetext{
“Temos que entender que em algumas religiões o processo de sedação não é compatível ou não é visto como uma conduta correta e que isso pode trazer prejuízos futuros segundo a crença e a espiritualidade de cada um. Então eles optam, de repente, por enfrentar aquele sofrimento e para eles já está resolvido, e aí acaba que quem sofre é quem tem todos os princípios dos CP e que acreditaria que se fizesse alguma coisa poderia aliviar o sofrimento." (Hortênsia)
}

Portanto, se alguém opta por morrer com sofrimento, provavelmente a orientação dessa decisão está alicerçada em valores religiosos, fundamentados no princípio da "santidade da vida" que não aceitaria interferências na vida humana já que "a vida é considerada como propriedade de Deus, dada ao homem em administração. É um valor absoluto que só a Deus pertence. O homem não tem nenhum direito sobre a vida própria e alheia"19 (p. 339). 
Assim, diante de uma decisão de rejeitar a SP, os profissionais sofrem a frustração de não poderem aplicar integralmente os recursos dos CP. Geralmente guiados pela ética deontológica, para os profissionais de saúde, a prática da SP, frente ao sofrimento, acaba se transformando num dever profissional, e não se poder cumpri-lo - a fim de minimizar o sofrimento do outro - por respeito à autonomia e seus valores, gera sofrimento na própria equipe. Por conseguinte, a vivência diária de um sofrimento e suas angústias necessariamente pode influenciar no processo de tomada de decisão pelo uso da SP. Ao passo que a ponderação cuidadosa dos fatos, dos deveres e valores, a fim de diminuir as incertezas, é considerada, pelos profissionais, como uma análise prudente envolvendo os familiares e a pessoa doente.

Como vemos, a principal referência para o uso prudente da SP é a bioética, e, na concepção de $\mathrm{Gracia}^{4}$, também a axiologia; não apenas para esclarecer a fronteira entre a prática da SP e a eutanásia, mas, também, para garantir a autonomia do doente/familiares. Com relação ao limite entre a SP e a eutanásia, para os profissionais da equipe de $\mathrm{CP}$, percebemos que há um acompanhamento do avanço do conhecimento aliado à experiência.

Para os profissionais, as práticas da SP e da eutanásia "(...) são diferentes" (Hortênsia). Enquanto: "para muito familiares elas parecem a mesma coisa e aí temos que desmistificar uma coisa da outra e conversar com a família para esclarecer as diferenças" (Hortênsia).

Embora os profissionais demonstrem convicção das diferenças entre as práticas, sobre essa questão existe um forte debate na literatura que revela controvérsias sobre diferenças e semelhanças entre SP e eutanásia e que aprofunda a problemática no campo da prática. As polêmicas que envolvem as discussões ao longo dos últimos anos têm-se centrado na modalidade de SP "contínua e profunda", isto é, a sedação que suprime a consciência da pessoa doente até a morte. Particularmente, esta é a forma de sedação - que muitos autores denominam de "sedação terminal" porque, normalmente, é aplicada próxima do momento da morte - que levou a bioética ao debate de questões que envolvem tais práticas ${ }^{2}$.

Há unanimidade em afirmar que o que diferencia a SP da eutanásia - dentre outros fatores relacionados - é a "intencionalidade do ato". Por exemplo, segundo a Sociedade Italiana de CP, a distinção empírica e moral da SP em relação à eutanásia, referem-se a três elementos constitutivos do procedimento terapêutico: 1) intenção; 2) tipos de fármacos, dosagem e via de administração; 3 ) resultado final ${ }^{20}$.

Mas de qual intencionalidade se pode falar? Como garantir a transparência da intenção? Para se chegar a uma resposta minimamente coerente, é preciso considerar que, na SP, não se tem a intenção de abreviar a vida do sujeito doente como meio ou instrumento para se chegar a um fim (objetivo), que é aliviar o sofrimento da pessoa e, em consequência, da sua família. Enquanto, na prática da eutanásia, a intenção é a abreviação da vida da pessoa doente para se atingir o objetivo que é interromper o sofrimento.

Segundo os profissionais de saúde entrevistados, a intenção é fundamental para a distinção:

"As diferenças entre SP e eutanásia são sutis, pois são diferenças éticas baseadas naquilo que você pretende fazer. Na eutanásia você quer abreviar a vida do paciente; no suicídio assistido você está ajudando o paciente abreviar sua própria vida e na SP você sabe que a vida do paciente vai se encerrar em curto prazo de tempo e o objetivo é que ele passe este momento 'dormindo'. O objetivo da SP não é abreviar o tempo de vida do paciente." (Margarida)

"A eutanásia, ela realmente abrevia a vida, com a SP se morre com qualidade de vida, sem dor e sem sofrimento emocional. Trabalha-se com a qualidade de vida e o bem-estar do paciente." (Orquídea)

Retomando o princípio da autonomia, conclui-se, do ponto de vista ético, tanto na SP quanto na eutanásia, o respeito a este princípio é condição essencial para a licitude moral do ato. Satisfeito tal requisito, compreendemos que a intencionalidade refere-se tanto ao uso dos meios, como ao resultado 
a que se quer chegar. Na SP, utilizam-se fármacos sedativos em doses apropriadas; o processo é controlado em virtude do resultado a que se quer chegar: o alívio do sofrimento. Na eutanásia e no suicídio assistido, os fármacos utilizados podem ser sedativos, mas administrados em doses letais, em virtude do resultado desejado - antes de tudo pela pessoa doente. A intencionalidade de ambos os atos se confirma nos resultados, isto é, no ato concreto, vale dizer: o alívio (minimização) do sofrimento - na SP; a interrupção (imediata) do sofrimento pela morte - na eutanásia. Intenção e resultado definem o respectivo ato: a supressão da consciência e o consequente alívio do sofrimento, na SP; a morte, e a consequente interrupção do sofrimento, na eutanásia.

Não se trata de uma distinção com fundamentação ética utilitarista. O utilitarismo considera somente as consequências para definir se uma ação é boa ou má21. Se considerarmos a importância da intencionalidade, estamos mais próximos de uma ética de responsabilidade, segundo a qual, " (...) todos têm direito de participar em um processo livre e equitativo de deliberação" 4; meios e fins são igualmente importantes.

No decorrer das entrevistas, os profissionais demonstraram preocupação em explicitar as diferenças entre a SP e a eutanásia, podendo sugerir, por trás dos relatos, que uma eventual abreviação da vida, devido ao uso da sedação, poderia identificá-la com a eutanásia. Difícil, porém importante, é compreender se essa preocupação se fundamenta em normas morais/éticas, e/ou normas legais. Do seguinte relato se depreende a preocupação com a distinção das práticas:

“Não tem relação nenhuma a SP e eutanásia, pois a SP não abrevia a vida, e ninguém tem o direito de fazer isso. A SP é para aliviar o sofrimento do paciente e a situação toda vai levar a um acordo comum para um benefício para ele. Não se faz nada para abreviar a vida de ninguém, ao contrário, queremos o alívio do sofrimento para a pessoa morrer dignamente, ou ao menos viver dignamente até o momento da morte." (Tulipa)

Quando Tulipa afirma que "ninguém tem o direito de fazer isso", não se pode confirmar que essa necessidade de distinguir as práticas deve-se ao fato de a eutanásia ser criminalizada no Brasil, ou se, além disso, os profissionais - sem generalizar - também considerariam a eutanásia, em casos extremos de sofrimento, moralmente ilícita. Esse seria conteúdo para outro estudo. Entretanto, cabe destacar que, independente das razões que os profissionais teriam para distinguir as práticas, tal distinção é fundamental não apenas do ponto de vista teórico, isto é, da ética, mas, sobretudo no âmbito da prática, enquanto ato moral. Somente assim se garante que a prática da SP, enquanto ato moralmente lícito, não seja também criminalizada legalmente.

Gracia, quando discute o princípio do duplo efeito, esclarece a sua posição acerca deste conflito ético. A eutanásia consiste sempre numa ação realizada no corpo de outra pessoa com a intenção direta de pôr fim à sua vida; a eutanásia é sempre e somente ativa. Por outro lado, a SP é um recurso para amenizar o sofrimento no processo de morrer de uma pessoa, a morte assistida com o devido cuidado ${ }^{4}$. Gracia não exclui a possibilidade da eutanásia em casos de exceções. Para ele, não existem regras morais absolutas, isto é, regras ou normas que não admitam exceções. Partindo desse pressuposto, acredita que a eutanásia jamais poderia se converter numa regra; e mais, defende que a eutanásia não pode ser usada como pretexto para se dispensar a prestação da assistência aprimorada aos pacientes terminais. Satisfeita tal condição, isto é, a morte assistida com o devido cuidado, mediante os $\mathrm{CP}$, a eutanásia jamais poderá ser vista senão como uma exceção. A norma tem de ser o respeito à vida. Não por acaso, a melhoria da assistência nas fases finais da vida se converteu no objetivo fundamental ${ }^{4}$. Objetivo que, de acordo com Berlinguer ${ }^{22}$, só pode ser alcançado por um sistema de saúde fundado no princípio da justiça social, cujo Estado garanta o acesso universal e equitativo aos CP. Assim, a assistência qualificada em fim de vida poderia se transformar em regra e, eventualmente, a eutanásia (legislada) em exceção. Pois, como afirma Gracia ${ }^{4}$, se os cuidados paliativos são importantes, o são por si mesmos, e não como meio para evitar a eutanásia.

Isto equivale a dizer que, mesmo no âmbito dos $\mathrm{CP}$, não poderemos nos abster de enfrentar e debater casos de pedido consciente - e persistente - de eutanásia. Os CP não os tornam irrelevantes, e somente com reflexão ética é que tais situações podem ser analisadas e deliberadas. 
Para se deliberar conflitos éticos na prática da SP, o processo de comunicação no âmbito da equipe e com a pessoa doente/familiares é fundamental, pois contribui para desmistificar a prática e compreender o que a pessoa doente realmente está necessitando diante do sofrimento insuportável. Um entrevistado afirmou que utilizam a SP após "um processo de comunicação com a família e às vezes até com o paciente" (Violeta), o que nos leva a inferir que, frequentemente, a decisão pelo uso da SP é feita pela família, e não pela pessoa doente, pois identificamos que se deixa para abordar a possibilidade de uso desse recurso quando, efetivamente, se detectou a necessidade, quando normalmente a pessoa doente já teve afetada a sua capacidade de comunicação e autonomia de decisão. Entretanto,

"A abordagem é muito relativa, depende da situação e do paciente. Tem paciente que não abordamos; não há tempo, às vezes, eles chegam a um grave estado clínico que não tem possibilidade de comunicação e conversamos com os familiares. Iniciamos a abordagem sobre a sedação quando começamos a identificar os sinais refratários; isso tudo te dá embasamento e segurança inclusive para conversar com essa família." (Violeta)

O uso da SP em fim de vida é uma ação complexa, e pode-se dizer que um dos motivos da dificuldade de abordagem antecipada com a pessoa doente e a família sobre a possibilidade da SP, é exatamente a dificuldade do diálogo sobre a morte e as doenças em fase terminal, num contexto social em que são verdadeiros tabus que impedem o diálogo e a reflexão, como se afirma:

"São difíceis estas conversas porque nossa população muitas vezes não fala sobre o processo de morrer e a morte. [...] Tem família que pede para não contarmos a real situação do paciente, dizendo que ele não sabe o que tem; e ao conversarmos com o paciente ele pede para não contarmos sua real situação aos familiares. Permanece uma conspiração do silêncio e ambos perdem um tempo precioso, que é o tempo da comunicação, da aceitação do processo de morrer para vivenciar juntos este momento." (Violeta)

O diálogo e a informação podem garantir uma compreensão apropriada e decisão autônoma, sendo aceitável que a família decida pela pessoa doente quando esta não puder mais fazê-lo, mas é adequado que ela saiba da sua vontade sobre como quer morrer. Por isso, na maioria dos casos, a abordagem precoce da SP seria essencial.

"Poderia ser feita precocemente, com o paciente lúcido, orientado, entendendo o que vai ser feito. Se isso fosse explicado antes, quem sabe o paciente pudesse conversar com a família, expressar sua vontade e daí a família se sentiria mais segura de estar decidindo o que fazer no momento em que ele não vai poder opinar." (Girassol)

Em suma, acredita-se que a pessoa doente e sua família só podem tomar uma decisão autônoma, pela SP, se devidamente informadas, por meio de um processo deliberativo - compartilhado entre equipe, família e sujeito doente -, enquanto "estratégia útil e relevante para equipes de saúde na análise, avaliação e indicação do melhor curso de ação para solução dos problemas" 23 (p. 114).

\section{Considerações finais}

No decorrer desse estudo, identificaram-se alguns importantes aspectos para a tomada de decisão prudente na prática da SP, que, como vimos, não é apenas uma manobra técnica. Ela deve seguir protocolos de aplicação de habilidades técnicas, mas, sobretudo, guiar-se pela ética. Sempre se deve obter o consentimento para se proceder à sedação de forma delegada ou estando implícita nos valores manifestados pelo paciente à família ou à equipe. Do ponto de vista das garantias éticas, o mais importante é que a equipe tenha identificado estes valores e desejos do paciente e/ou por meio da família, refletidos na história clínica. 
$\mathrm{Na}$ discussão dos "sentidos atribuídos à SP, princípios e valores implicados", identificamos o princípio da autonomia, permeado por valores morais e religiosos, como relevantes nas discussões e ações dos profissionais. Os sentidos atribuídos à SP, pelos profissionais entrevistados, acompanham a evolução conceitual proporcionada pelo próprio desenvolvimento científico sobre o assunto, que tem, cada vez mais, esclarecido os fatos clínicos, mas, também, seguem a evolução da reflexão ética.

No sentido de tomar decisões prudentes, os entrevistados sustentam suas condutas na ética principialista e na ética de responsabilidade; os princípios não são vistos como absolutos e o sentido da intencionalidade está na deliberação coletiva. Na tomada de decisão, os profissionais buscam captar os valores morais, culturais e religiosos da pessoa doente/familiares, pois são relevados estes e outros que podem implicar conflitos diante da SP.

Importante destaque ocorre na distinção entre SP e eutanásia, em que os entrevistados colocam o alívio do sofrimento, perante a morte, como último recurso e objetivo da SP. Essa intenção, que deve se confirmar nos resultados da ação, isto é, confortar a pessoa doente sem intervir na temporalidade do processo de morrer, é o que caracteriza a prática da SP.

Mesmo diante da delimitação entre SP e eutanásia, a que chegamos, os limites são tênues, fazendo com que a ética seja suporte fundamental aos profissionais para o exercício da SP enquanto ato moralmente lícito. Neste sentido, o processo de tomada de decisão sobre a SP deve ocorrer como resultado do trabalho de equipe interdisciplinar, a partir da vontade e/ou consentimento da pessoa enferma/familiares, adequadamente informados sobre a possibilidade/finalidade da utilização desse recurso e suas consequências indesejáveis, sobretudo a diminuição progressiva do nível de consciência até sua supressão, decorrente da sedação contínua e profunda - que delimita o fim da vida biográfica da pessoa doente.

\section{Colaboradores}

Melisse Eich responsabilizou-se pela construção do artigo em todas as etapas, sob a orientação acadêmica e revisão de Marta Inez Machado Verdi. Mirelle Finkler participou da discussão e revisão crítica do texto. Pedro Paulo Scremin Martins colaborou na pesquisa bibliográfica, redação e formatação do texto.

\section{Referências}

1. Connor S, Gómez-Batiste X. Building integrated palliative care program and services. Barcelona: Liberdúplex; 2017.

2. Pessini L, Barchifontaine CP. Problemas atuais de bioética. 11a ed. São Paulo: Loyola; 2014.

3. Chater S, Viola R, Paterson J, Jarvis V. Sedation for intractable distress in the dying-a survey of experts. Palliat Med. 1998; 12(4):255-69.

4. Gracia D. Pensar a bioética: metas e desafios. São Paulo: Loyola; 2010.

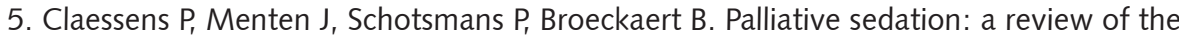
research literature. J Pain Symptom Manage. 2008; 36(3):310-33. 
6. Cowan JD, Walsh D. Terminal sedation in palliative medicine-definition and review of the literature. Support Care Cancer. 2001; 9(6):403-7.

7. Cherny NI. Palliative sedation. In: Bruera E, Higginson I, von Gunten CF, Morita T, editors. Textbook of palliative medicine and supportive care. London: CRC Press; 2016. p. 1009-20.

8. Gracia D, Feito L, Moratalla TD, González MAS, Martínez JA. Ética y ciudadanía: construyendo la ética. Madrid: PPC Editorial y Distribuidora; 2016.

9. Rego S, Palácios M. A finitude humana e a saúde pública. Cad Saude Publica. 2006; 22(8):1755-60.

10. Floriani CA, Schramm FR. Desafios morais e operacionais da inclusão dos $C P$ na rede de atenção básica. Cad Saude Publica. 2007; 23(9):2072-80.

11. Minayo MCS. O desafio do conhecimento. 14a ed. São Paulo: Hucitec; 2014.

12. Conselho Nacional de Saúde (BR). Resolução CNS n 466, de 12 de Dezembro de 2012. Aprova as diretrizes e normas regulamentadoras de pesquisas envolvendo seres humanos. Diário Oficial da União. 13 Jun 2013.

13. Mercadante S, Intravaia G, Villari P, Ferrera P, David F, Casuccio A. Controlled sedation for refractory symptoms in dying patients. J Pain Symptom Manage. 2009; 37(5):771-9.

14. Sales JPI, Olarte JMN, Trota RA, Aguilar AG, Vidal PL, Sánchez DM, et al. Aspectos éticos de la sedación en CP. Med Paliat. 2002; 9(1):41-6.

15. Committee on National Guideline for Palliative Sedation. Royal Dutch Medical Association. Guideline for palliative sedation. Utrecht, NLD: KNMG; 2009.

16. Maltoni M, Pittureri C, Scarpi E, Piccinini I, Martini F, Turci P, et al. Palliative sedation therapy does not hasten death: results from a prospective multicenter study. Ann Oncol. 2009; 20(7):1163-9.

17. Maltoni $M$, Scarpi $E$, Rosati $M$, Derni S, Fabbri L, Martini $F$, et al. Palliative sedation in end-of-life care and survival: a systematic review. J Clin Oncol. 2012; 30(12):1378-83.

18. Chiu TY, Hu WY, Lue BH, Cheng SY, Chen CY. Sedation for refractory symptoms of terminal cancer patients in Taiwan. J Pain Symptom Manage. 2001; 21(6):467-72.

19. Junges JR. A vida como bem fundamental do homem. Perspect Teol. 1993; 25(97):339-45.

20. Ambroset S, Bassolino V, Caraceni A. Raccomandazioni della SICP sulla sedazione terminale/sedazione palliativa. Riv Ital Cure Palliat. 2008; 1:16-36.

21. Taboada P. Bioethical principles in palliative care. In: Bruera $E$, Higginson I, von Gunten CF, Morita T, editors. Textbook of palliative medicine and supportive care. London: CRC Press; 2016. p.105-18.

22. Berlinguer G. A bioetica quotidiana. Firenze: Giunti; 2010.

23. Nora CRD, Zoboli ELCP, Margarida MV. Deliberação ética em saúde: revisão integrativa da literatura. Rev Bioet. 2015; 23 (1):114-23. 
Eich M, Verdi MIM, Finkler M, Martins PPS. Principios y valores implicados en la práctica de la sedación paliativa y la eutanasia. Interface (Botucatu). 2018; 22(66):733-44.

El objetivo de este estudio fue entender los sentidos atribuidos por los profesionales de salud a la práctica de la sedación paliativa en el proceso de muerte, las relaciones de esta práctica con la eutanasia, así como los valores considerados importante y que sirven de subsidio al equipo de cuidados paliativos en la toma de decisión. Se trata de una encuesta exploratoria y descriptiva de abordaje cualitativo, con base en la hermenéutica dialéctica. Los resultados indican que los sentidos atribuidos por los profesionales entrevistados acompañan el desarrollo científico, los cuales han buscado aclarar los hechos clínicos de cada proceso de toma de decisión y los valores implicados, siguiendo la evolución de la reflexión ética sobre la práctica de la sedación paliativa y la eutanasia. En el ámbito de la reflexión ética, los principios no son vistos como absolutos, puesto que, al considerar los valores, los profesionales analizan las circunstancias y las consecuencias presentes en las decisiones.

Palabras clave: Sedación profunda. Cuidados paliativos. Bioética. Eutanasia.

Submetido em 17/10/2016. Aprovado em 16/08/2017. 